$\stackrel{N / N}{=}$

Global burnals Inc.

है

\title{
Arthroscopic Excision of Calcification in Lateral Collateral Ligament of the Knee with Direct Lateral (Bengaluru Chandrashekar) Portal
}

By Chandrashekar Puttaswamy, Nataraj Honnavalli Mallappa, Nagaraja Handenahally

\& Srinivasula Reddy Avula

Introduction- Calcium apatite deposition disease (CADD) is a common entity characterized by deposition of calcium apatite crystals within and around connective tissues, usually in a periarticular location ${ }^{1}$. Many different locations of CADD have been described amongst which, lateral collateral ligament $(\mathrm{LCL})$ of the knee is a rare location ${ }^{2}$. The first ever case of calcific deposits in the lateral collateral ligament of the knee was reported by Anderson et al ${ }^{3}$ in 2003. A few isolated case reports of LCL calcification are published in the literature ${ }^{4,5}$ but arthroscopic excision of calcific deposit in LCL has not been described yet in the literature. Here we are describing 2 cases of arthroscopic excision of calcific deposits in LCL of the knee by a new portal called 'Direct lateral portal' for the knee.

GJMR-H Classification: NLMC Code: WE 300

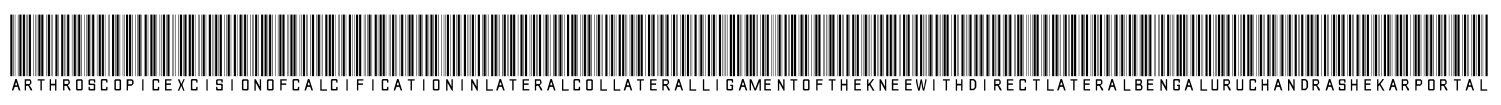

Strictly as per the compliance and regulations of:

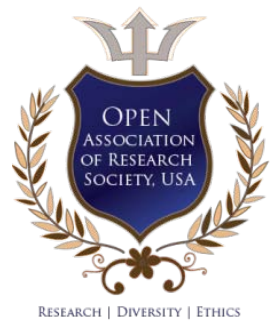

(C) 2019. Chandrashekar Puttaswamy, Nataraj Honnavalli Mallappa, Nagaraja Handenahally \& Srinivasula Reddy Avula. This is a research/review paper, distributed under the terms of the Creative Commons Attribution-Noncommercial 3.0 Unported License http://creativecommons.org/licenses/by-nc/3.0/), permitting all non-commercial use, distribution, and reproduction in any medium, provided the original work is properly cited. 


\title{
Arthroscopic Excision of Calcification in Lateral Collateral Ligament of the Knee with Direct Lateral (Bengaluru Chandrashekar) Portal
}

\author{
Chandrashekar Puttaswamy ${ }^{\alpha}$, Nataraj Honnavalli Mallappa ${ }^{\sigma}$, Nagaraja Handenahally ${ }^{\rho}$ \\ \& Srinivasula Reddy Avula ${ }^{\omega}$
}

\section{InTRODUCTION}

alcium apatite deposition disease (CADD) is a common entity characterized by deposition of calcium apatite crystals within and around connective tissues, usually in a periarticular location'. Many different locations of CADD have been described amongst which, lateral collateral ligament $(\mathrm{LCL})$ of the knee is a rare location'2. The first ever case of calcific deposits in the lateral collateral ligament of the knee was reported by Anderson et al ${ }^{3}$ in 2003. A few isolated case reports of $L C L$ calcification are published in the literature 4,5 but arthroscopic excision of calcific deposit in LCL has not been described yet in the literature. Here we are describing 2 cases of arthroscopic excision of calcific deposits in LCL of the knee by a new portal called 'Direct lateral portal' for the knee.

\section{il. CASE Report}

Both cases were operated after institutional ethical committee clearance. The 2 cases reported here were operated using the New "Direct Lateral Portal/Bengaluru Chandrashekar Portal" after obtaining written informed consent with a prior explanation of the procedure.

Case 1- A 50-year-old lady presented with pain in the left knee of one year duration. There was no improvement with conservative treatment in the form of anti-inflammatory medication and physiotherapy. X-ray of the knee showed calcification in the LCL region (Fig. 1a 1b).

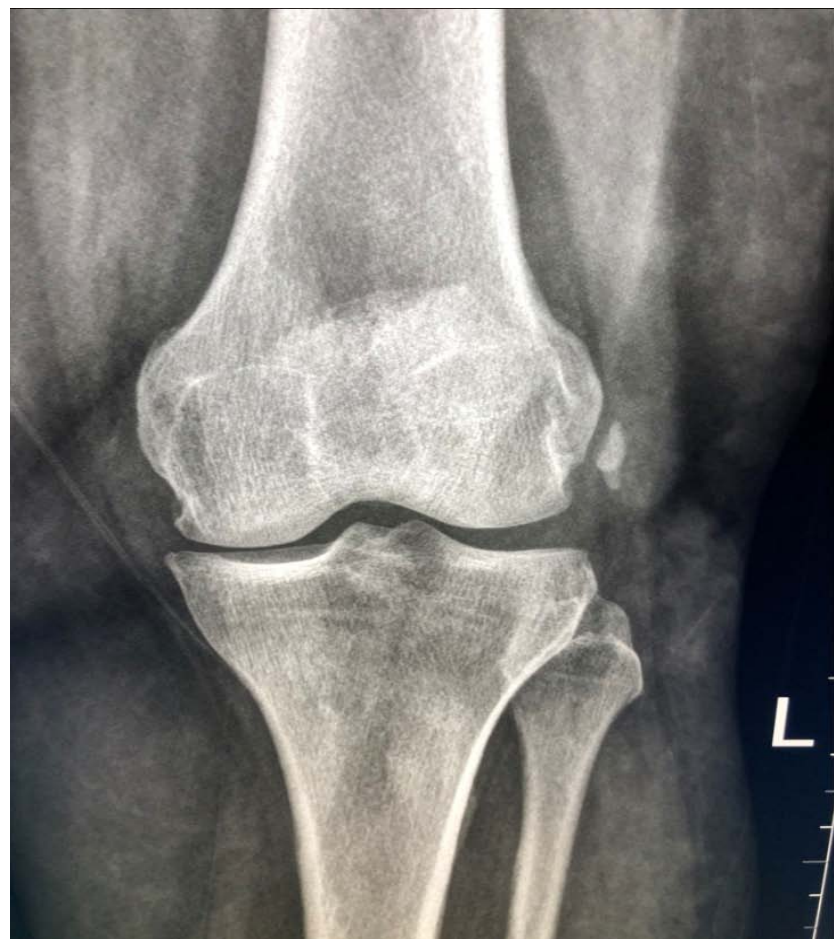

Figure la: Calcification in LCL Region 


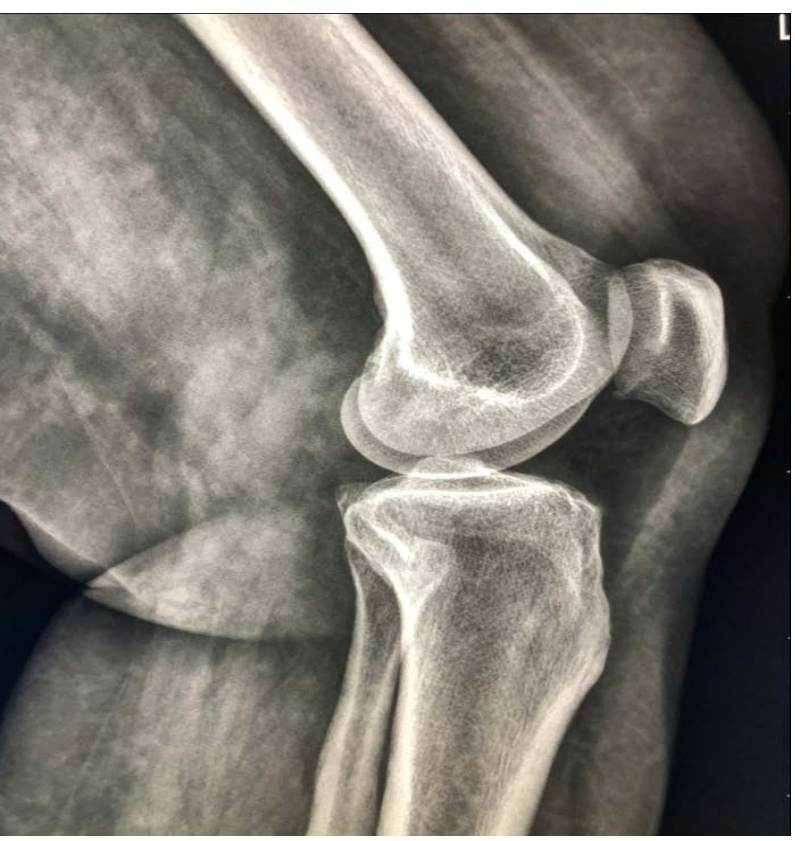

Figure 1b: Calcification in LCL Region

Fig. 1a and 1b: X-ray AP and Lateral views showing calcific deposits over lateral condyle

MRI scan showed intra-substance calcification in the LCL near the femoral attachment and associated medial meniscus root tear (Fig. 2a, 2b). With no improvements with medications and conservative

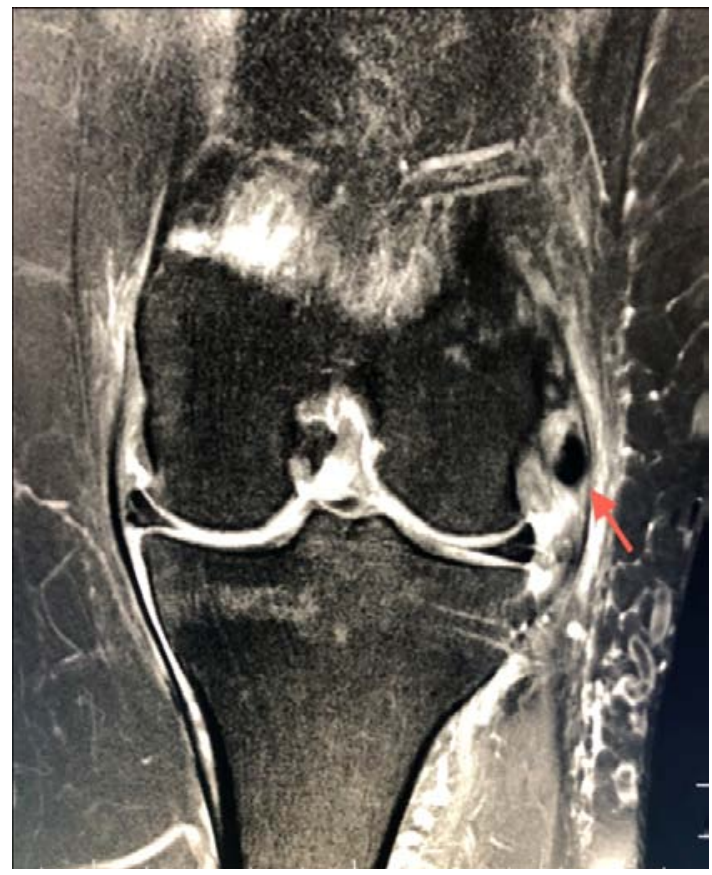

Figure 2a: Calcification near Femoral Attachment method of treatment for 1 year, the patient opted for our treatment plan of arthroscopic meniscal root repair with concomitant arthroscopic excision of LCL calcification.

Fig. 2a and 2b: MRI images showing calcific deposits in LCL and medial meniscus root tear (Arrows)

Case 2- A 54-year-old lady presented with left knee pain of 6 months duration. She was treated with anti-inflammatory medications and physiotherapy. But the symptoms showed no improvement. X-ray showed calcific deposits in the lateral side of the knee.

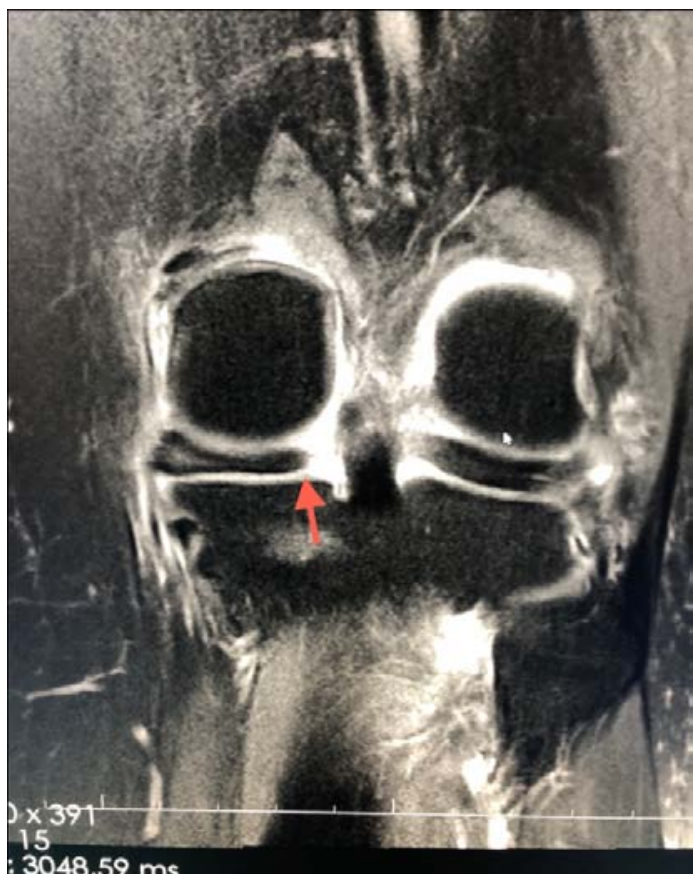

Figure 2b: Medial Meniscus Root Tear

MRI showed calcific deposits at the femoral attachment of LCL. Since her pain interfered with daily activities, arthroscopic excision of calcific deposits was considered. 
The technique of arthroscopic excision of calcification in LCL.

Under spinal anesthesia, the patient is placed in supine position with the limb held by thigh holder, so that the knee is in a hanging down position, making a flexion angle of 90 degrees. Standard anterolateral and anteromedial portals were made. The knee was then positioned into extension with arthroscope in the anterolateral portal. A needle was placed over lateral epicondyle under IITV guidance (Fig. 3). With the arthroscope in the anterolateral portal, the superolateral portal was made. Bands over the lateral gutter (Fig. 4 a) were cleared and then the arthroscope was moved inferiorly and posteriorly until the needle over the lateral epicondyle (Fig. 4 b) was visualized. A direct lateral portal, $1 \mathrm{~cm}$ inferior and $1 \mathrm{~cm}$ posterior to the lateral epicondyle with the knee in extension was made (Fig. $4 \mathrm{C}$ and d). The calcific deposits in LCL were visualized (Fig. 4 e).

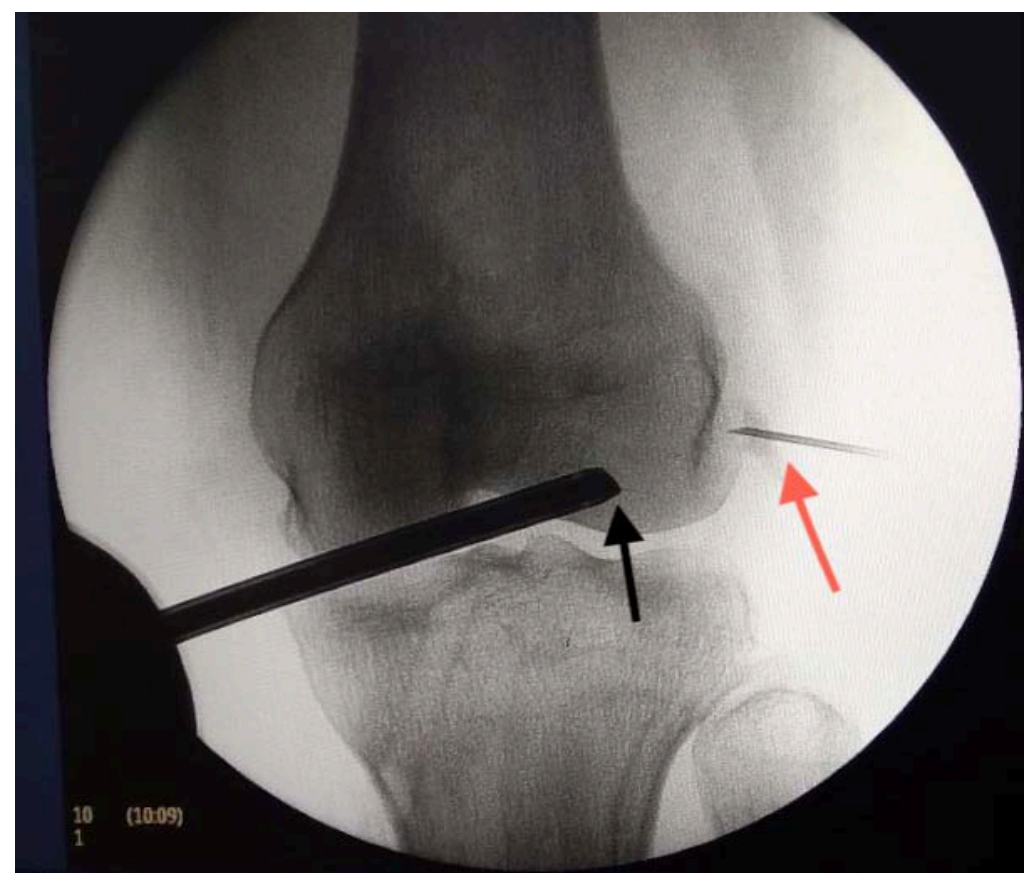

Figure 3: Lateral Epiconcdyle Needle

Fig. 3: Needle (Red arrow) placed over Calcific deposits under IITV* guidance (*IITV- Image intensifier television)and arthroscope( Black arrow) viewing from the anterolateral portal and knee in Extension

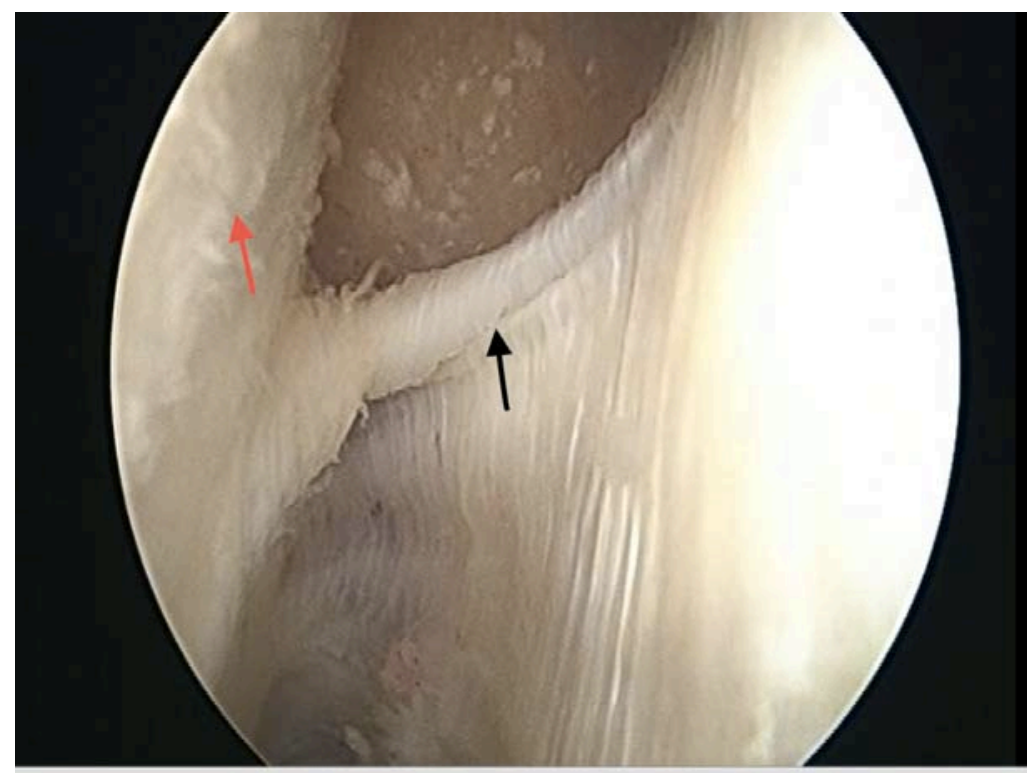

Figure 4a: Bands over Lateral Gutter 


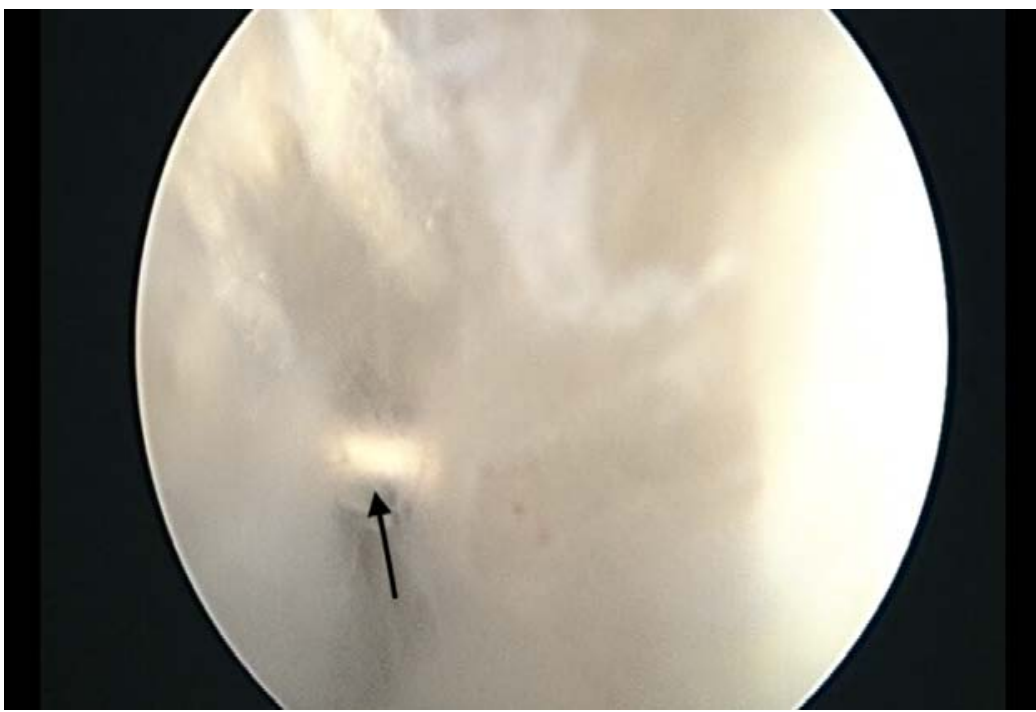

Figure 4b: Lateral Epicondyle

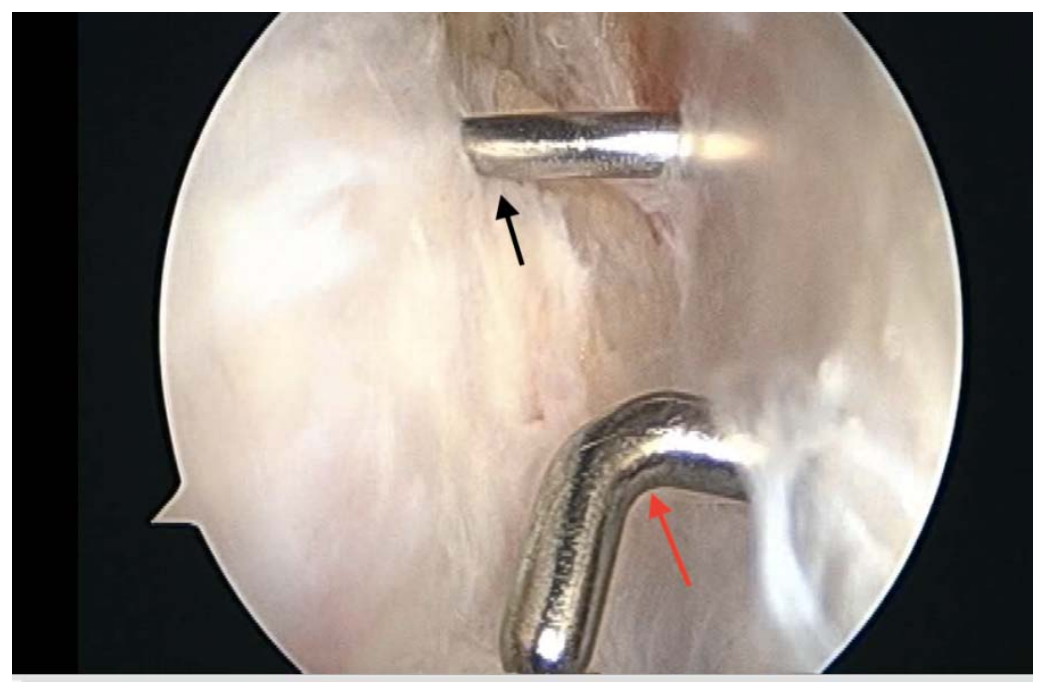

Figure 4c: Direct Lateral Portal

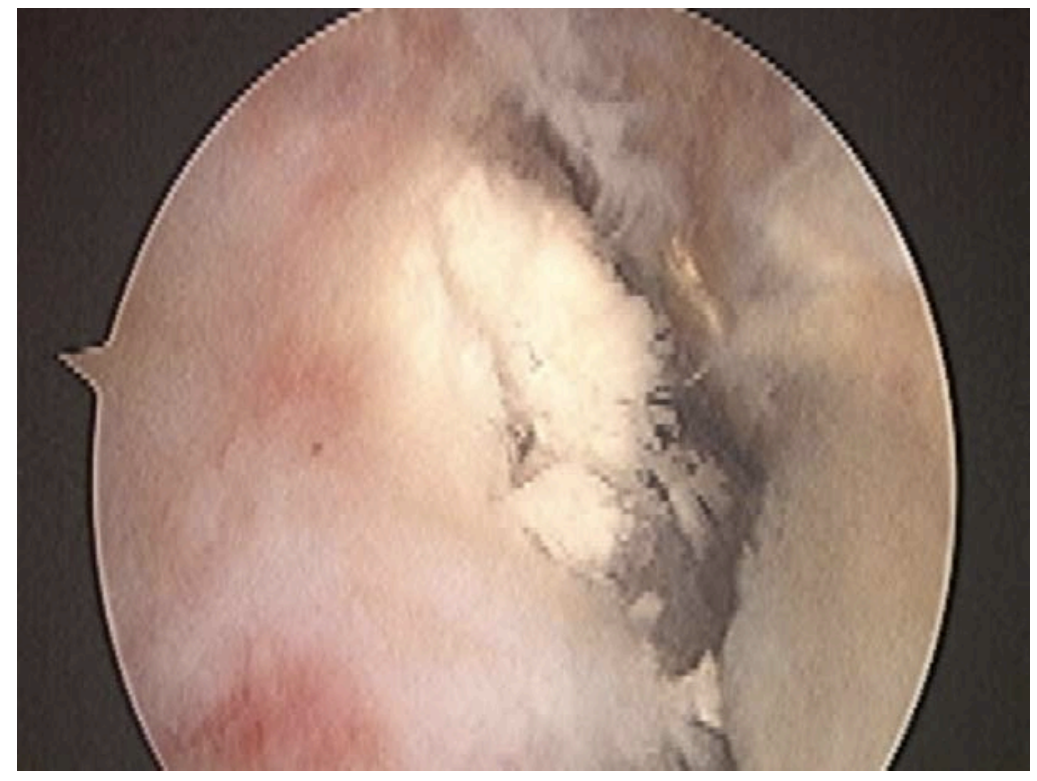

Figure 4d: Direct Lateral Portal 


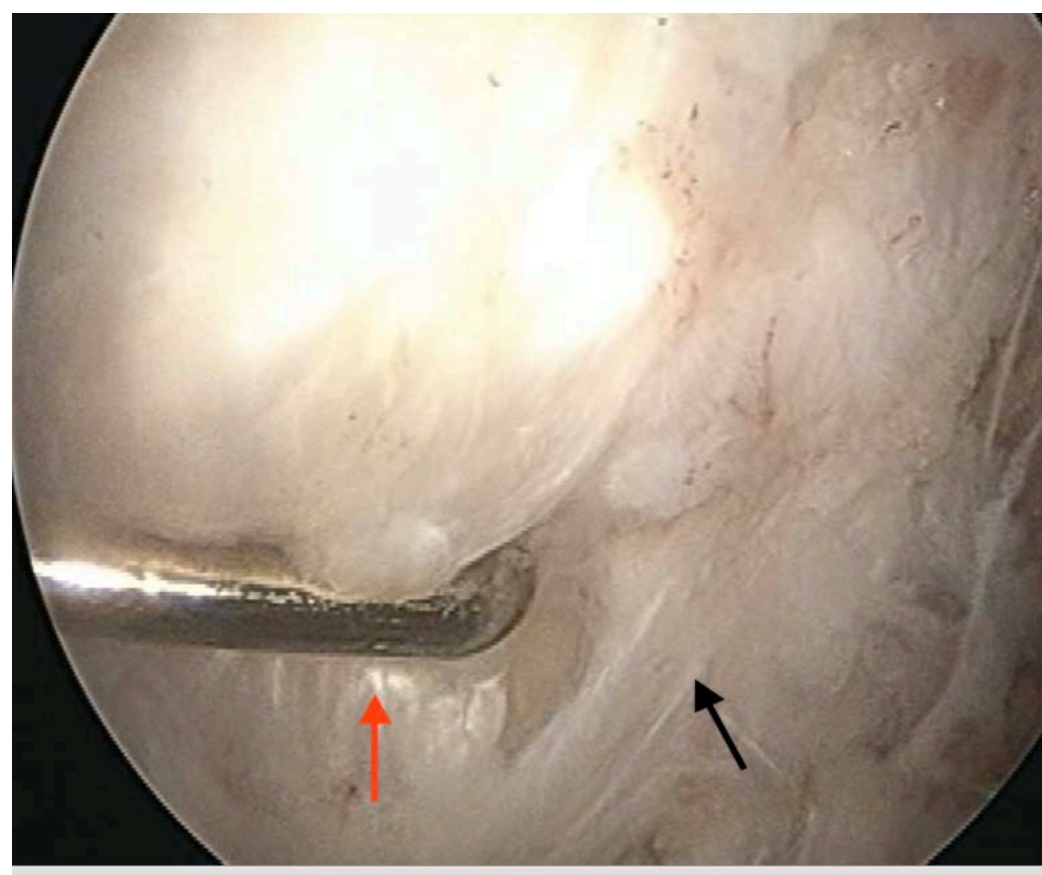

Figure 4e: Calcific Deposits in LCL

Fig. 4 a-e: (a) Lateral Band in the Lateral Gutter -(Red Arrow-Lateral Femoral Condyle, Black Arrow-Lateral Band) (b) Needle (Black arrow) over epicondyle identified from anterolateral portal (c) Probe in direct lateral portal (Red arrow) and Needle over lateral epicondyle (Black arrow) (d) Calcific deposits in the LCL, (e) LCL (Black Arrow) and Popliteus (Red Arrow) as seen from direct lateral portal

The LCL and popliteus were dissected (Fig. 5), calcific deposits in the LCL was debrided by switching the arthroscope and shaver between the anterolateral portal and direct lateral portals. A small part of the LCL was shaved at the area of calcific deposit and all the

deposit was squeezed out. Intactness of the LCL was confirmed with Varus stress test and the opening of the lateral joint was confirmed under IITV guidance (Fig. 6 a, 6b).

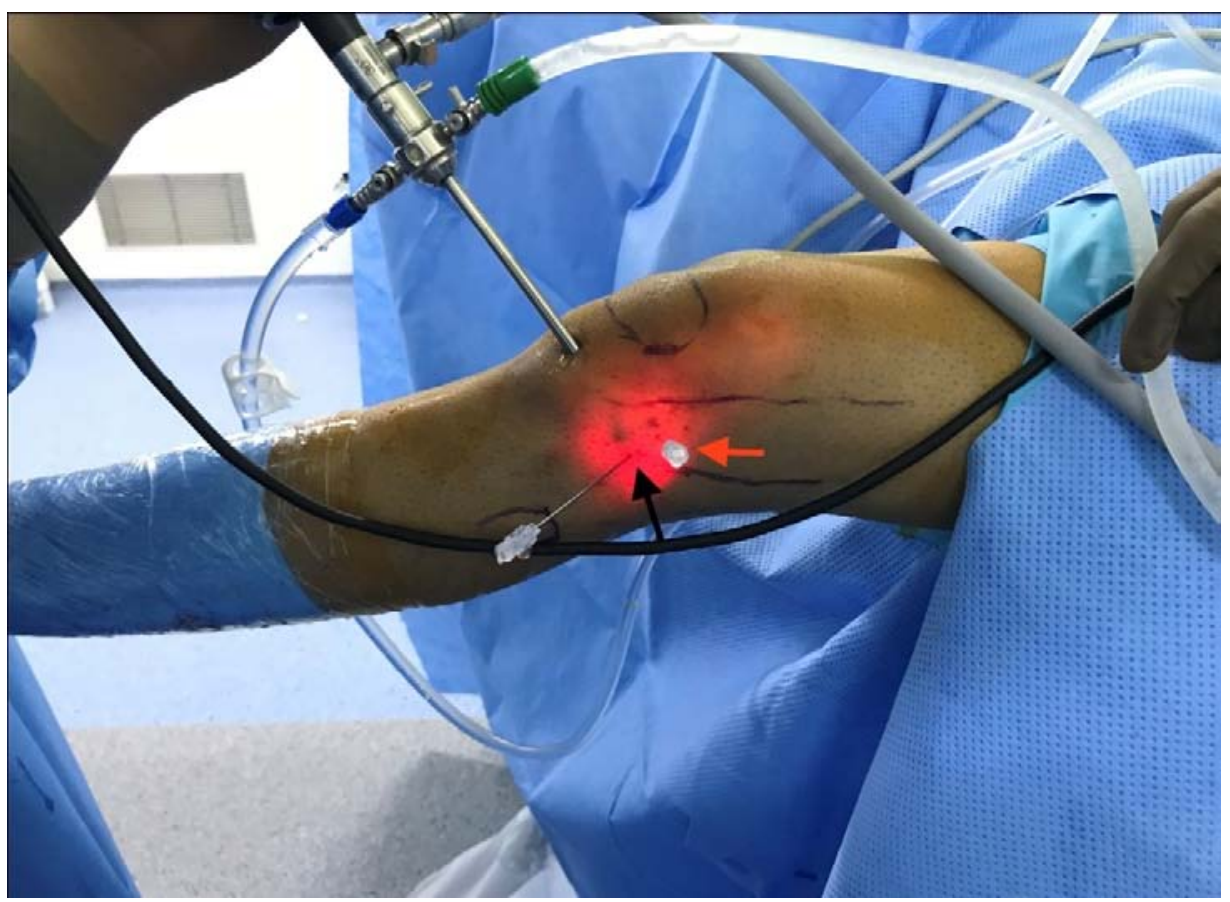

Figure 5: LCL and Popliteus

Fig. 5: Direct lateral portal-(Red Arrow-Needle over lateral epicondyle and Black arrow-Direct Lateral Portal) 


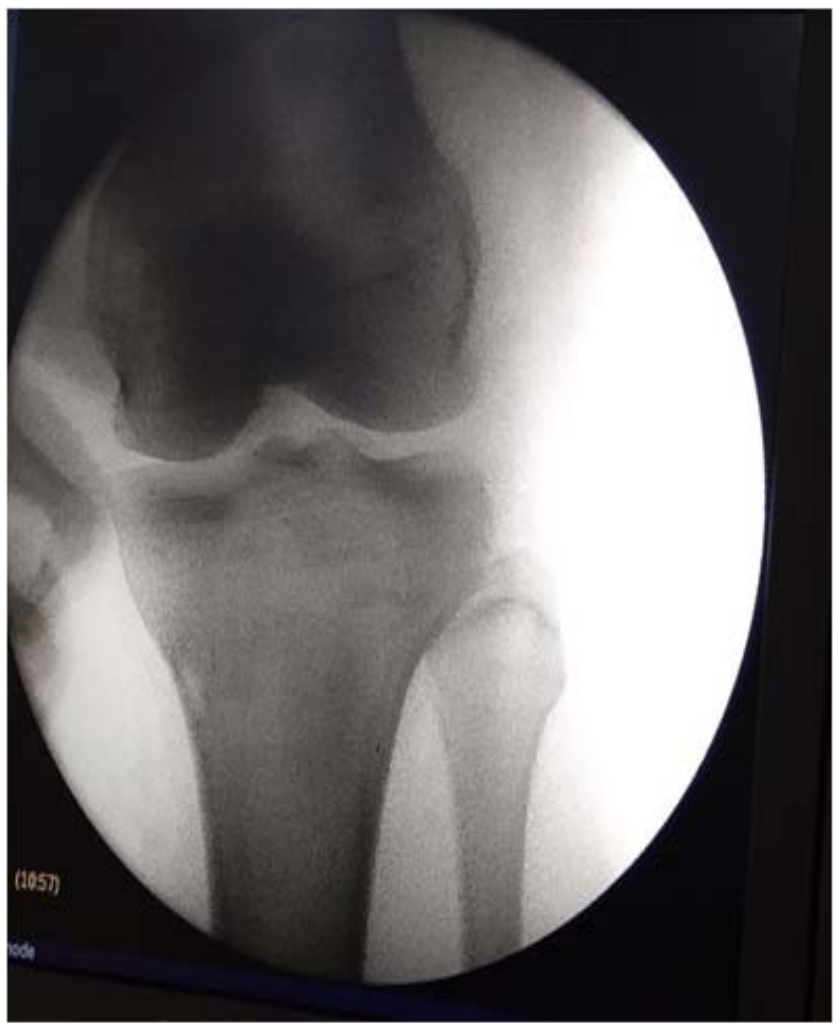

Figure 6a: IITV Guidance

Fig. 6: a -IITV image after removal of calcific deposits

Medial meniscus root tear was repaired with pull-through suture technique.

\section{Discussion}

Calcific deposits in the lateral collateral ligament of the knee has been described in the literature ${ }^{1-5}$. The condition is described in the middle and old age group ${ }^{6}$.Open excision of calcific deposit has also been described in the literature ${ }^{7,8}$, but arthroscopic excision has not been described in the literature. In a study by Hyoung Hoo Kim et $\mathrm{al}^{9}$, they performed open excision of the calcific deposit which led to the disruption of the ligament, so the ligament had to be repaired back. To prevent ligament injury by the open technique, arthroscopic excision was conceptualized. Our concept of arthroscopic excision for the lateral side of the knee is inspired from a case report by Shenoy PM et al who excised calcium deposit from popliteus ${ }^{10}$.

We considered the feasibility of direct lateral portal and extensively studied and planned the portal. We performed cadaver study on 2 knees at a cadaver lab and further dissected the knee to know the safety of the portal (Fig. 7 a). On cadaver dissection of the direct lateral portal, the skin was incised to reach lliotibial band (IT) (Fig. 7 b). IT band was excised to visualize lateral epicondyle (Fig. 7c and d), the upper part of LCL and popliteus.

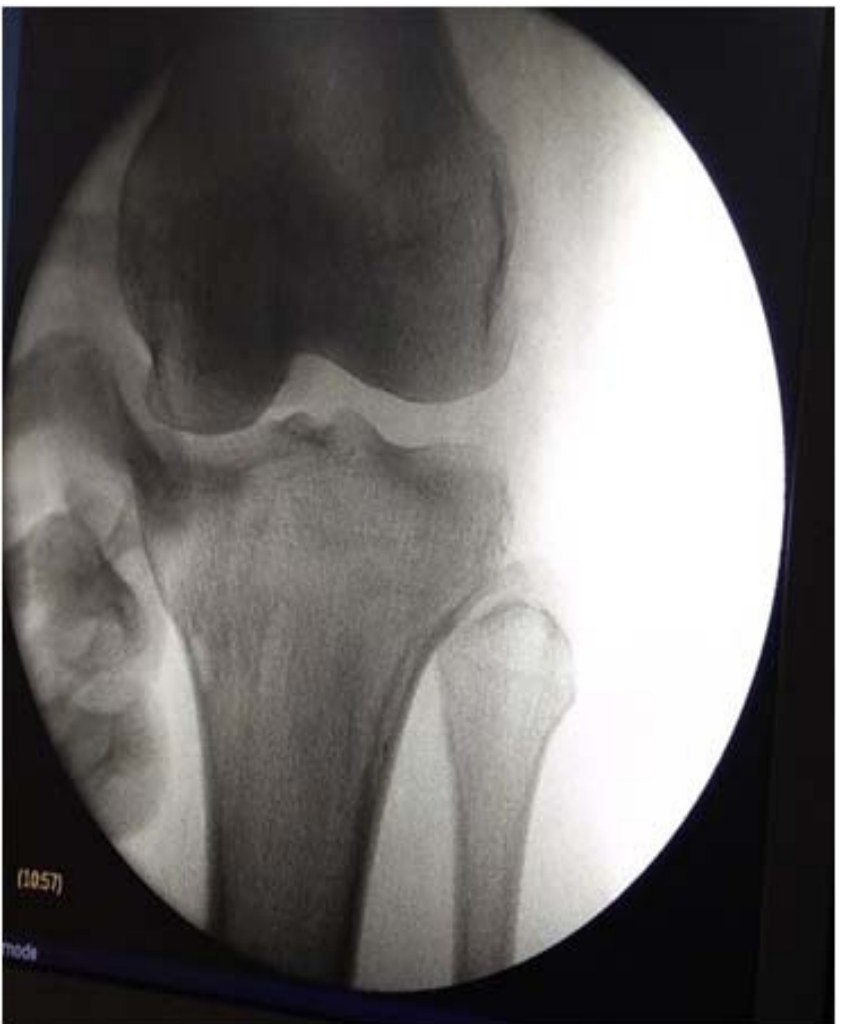

Figure 6 b: IITV Guidance

(b) Valgus test to reconfirm the intactness of LCL 


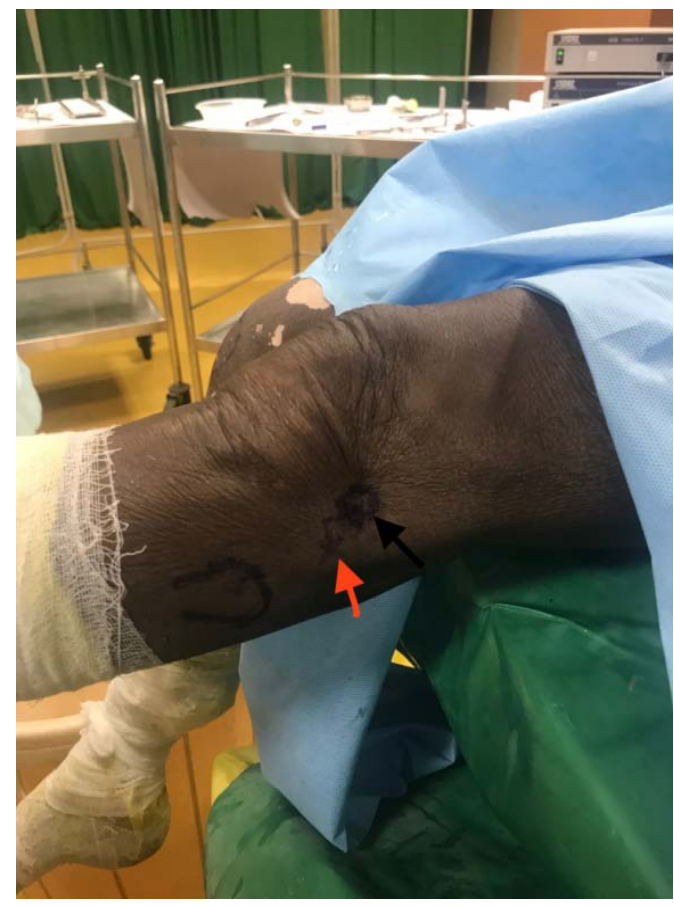

Figure 7a: Cadaver Knee

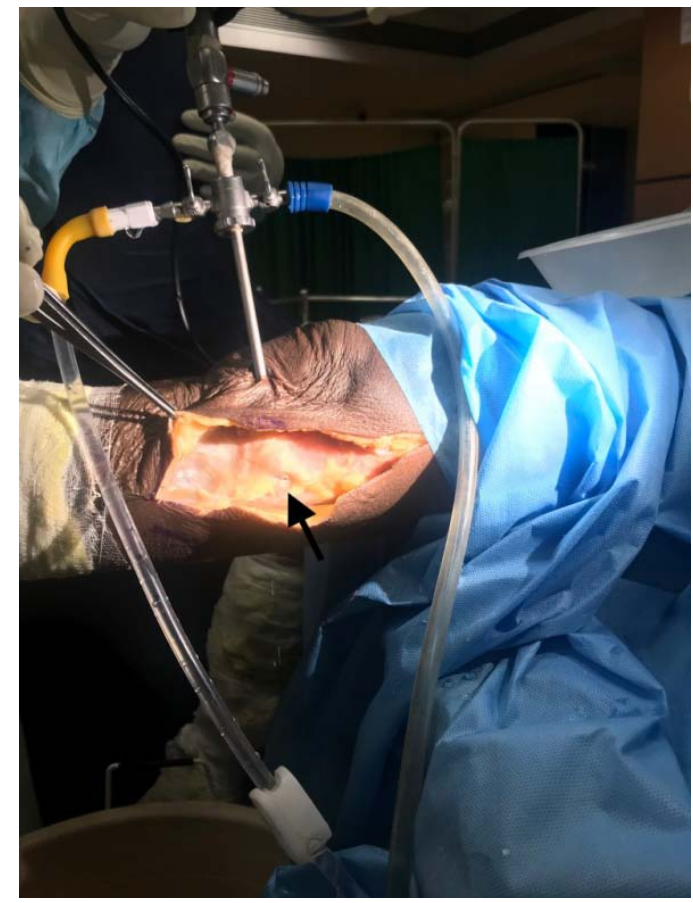

Figure 7b: lliotibial Band

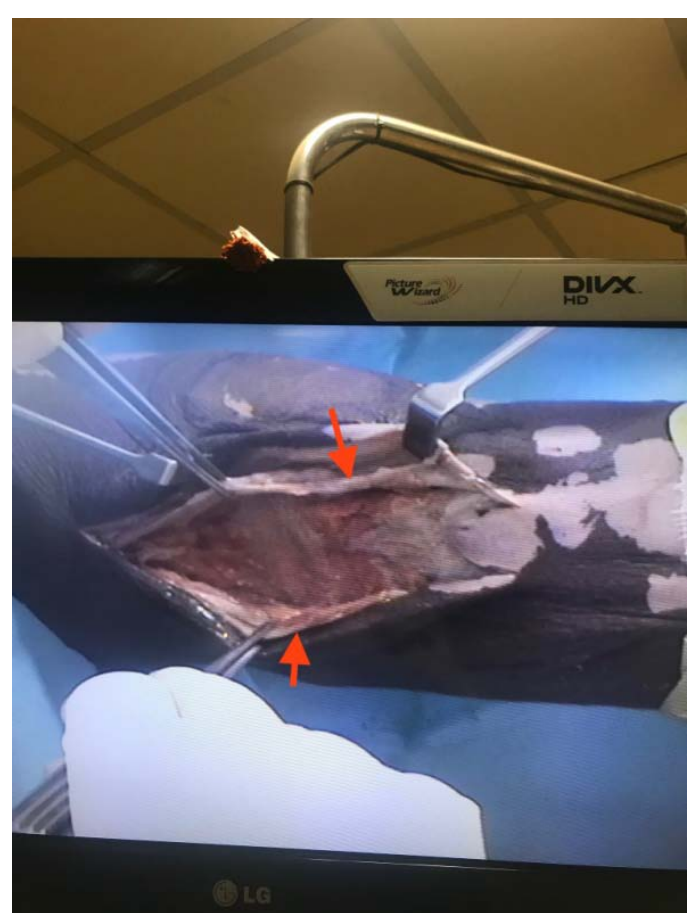

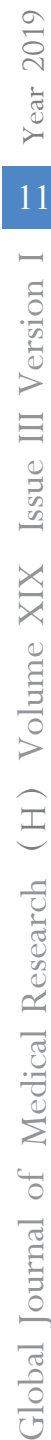

Figure 7c: Lateral Epicondyle 


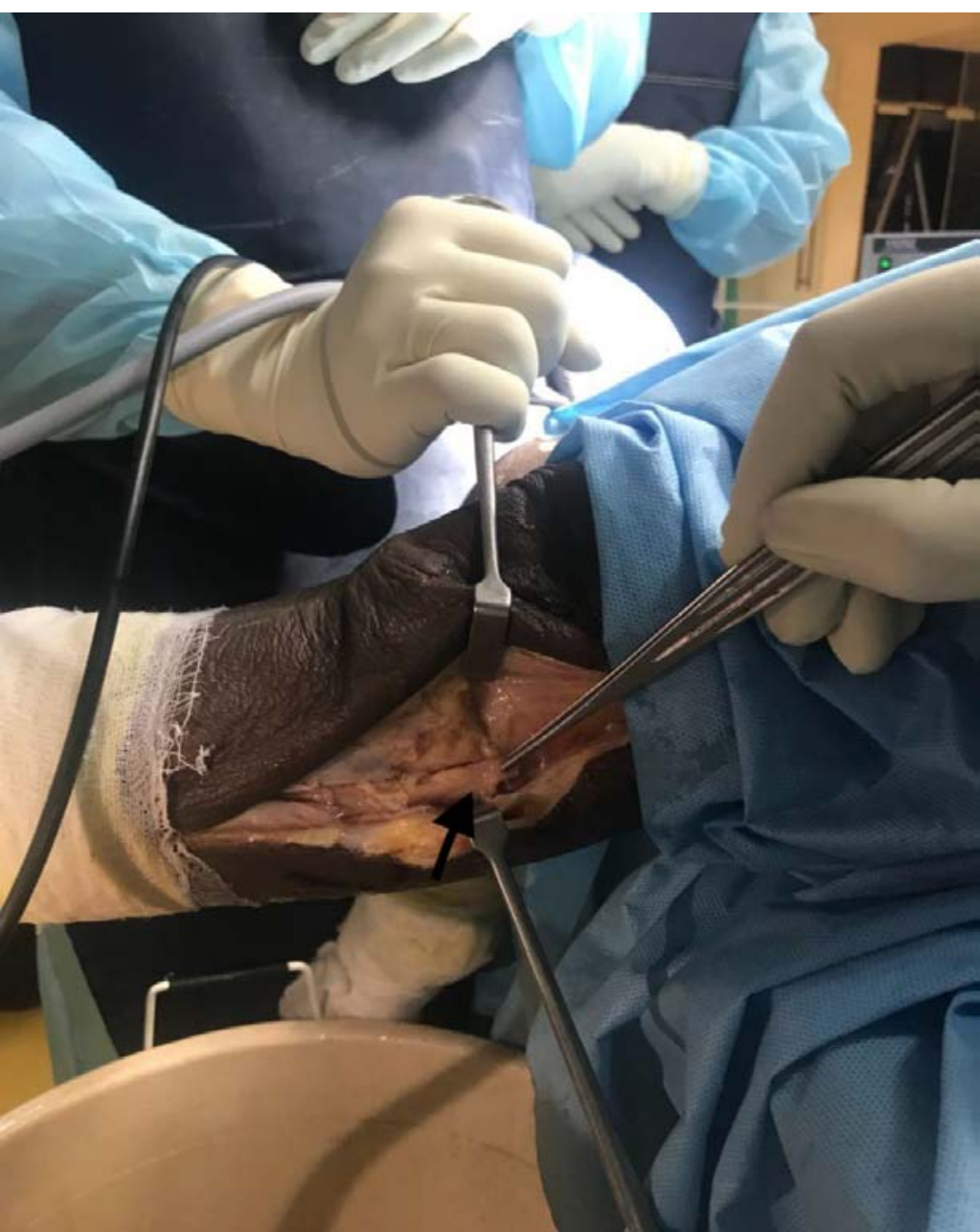

Figure 7d: Lateral Epicondyle

Fig. 7a-d: Cadaver dissection images. (a) Marking of lateral epicondyle (black arrow) and Direct Lateral portal (red arrow) (b) Direct Lateral Portal (black arrow) after skin flaps are dissected (c) lliotibial band (Red arrows) Portal is at safe distance from common peroneal nerve (d) $L C L$ detached from origin to confirm the exact origin of $L C L$ (Black arrow showing LCL)

Lateral epicondyle is $23.97 \mathrm{~mm}$ (sd 3.27) from the distal joint line and $24.42 \mathrm{~mm}$ (sd 3.14) from posterior joint line ${ }^{11}$. LCL insertion is located $1.4 \mathrm{~mm}$ proximal and $3.1 \mathrm{~mm}$ posterior to the lateral epicondyle in a small bony depression ${ }^{12}$. Popliteus attachment is $18.5 \mathrm{~mm}$ anterior and inferior to $\mathrm{LCL}$ insertion ${ }^{12}$. We safely dissected anterior to the common peroneal nerve and also did not damage the LCL fibers while making the portal.

Looking at the safety of this portal, we performed an arthroscopic debridement of calcific deposit in LCL in 2 patients. Along with standard anterolateral, anteromedial portals, a superolateral portal was made. Through the superolateral portal, bands in the lateral gutter were shaved with arthroscopic shaver and then a 'direct lateral portal' was done $1 \mathrm{~cm}$ inferior and $1 \mathrm{~cm}$ posterior to lateral epicondyle to visualize the LCL. This portal is anterior to the anterior border of the fibula, so there is no risk of injury to the common peroneal nerve. Calcific deposits in the LCL were identified and debrided by switching the arthroscope and shaver between the anterolateral portal and direct lateral portals. Finally, intactness of LCL was confirmed by varus stress test and recorded with C-arm. Postoperative X-ray (Fig. 8 a,b) shows the completeness of evacuation of calcification from the lateral side of the knee. 


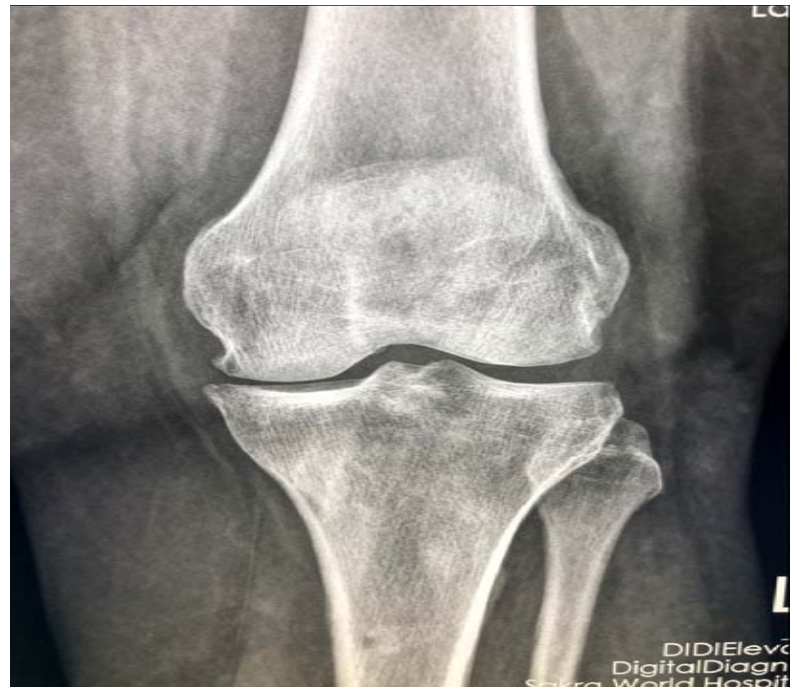

Figure 8b: X-ray Showing Complete Evacuation of Calcification

Fig. 8: Postoperative X-ray Knee AP and lateral views showing clearance of calcific deposits.

We are the first in the literature to describe arthroscopic excision of calcific deposit in LCL by a new portal 'Direct lateral portal' or 'Bengaluru Chandrashekar portal' for the knee. With this new innovative technique in arthroscopy, the utilization of arthroscopy technique has been amplified. We have utilized it to debride the calcific deposits in the femoral side of LCL and Popliteus, to visualize isometric point of femoral side reconstruction of anterolateral ligament (ALL), and also for visualization and repair of femoral avulsion of LCL and Popliteus.

\section{Declarations of Interest}

None

\section{Funding}

This research did not receive any specific grant from funding agencies in the public, commercial, or notfor-profit sectors.

\section{References Références Referencias}

1. Nicholas M._Beckmann. Review Article: Calcium Apatite Deposition Disease: Diagnosis and Treatment; Radiology Research and Practice. Volume 2016 (2016), Article ID 4801474, 16 pages.

2. Hayes C W, Conway W F. Calcium hydroxyapatite deposition disease. Radiographics 1990; 10: 1031-48.

3. Anderson S E, Bosshard Csteinbach L S, Ballmer F T. (2003). MR Imaging of calcification of lateral collateral ligament of the knee, a rare abnormality, and cause of lateral knee pain. AJR AmJ Rountgenol, 181, 199-202.

4. Imran Khan, Muhammad Iftikhar Rashid. Case report: Calcification of the Lateral Collateral Ligament of the Knee: A Rare Cause of Acute Knee 
Pain. Journal of the College of Physicians and Surgeons Pakistan 2012, Vol. 22 (6): 389-391.

5. Dhaval Gotecha et al. Case report: calcification of the lateral collateral ligament of the knee joint: a rare abnormality and cause of acute knee pain. International Jounal of Advances in Case Reports, 2015; 2(9): 539-541.

6. Karen Watura, Davyd Greenish, Martin Williams, and Jason Webb. calcific periarthiritis of the knee presenting with calcification within the lateral collateral ligament. BMJ Case Rep. 2015; 2015: bcr2014209041.

7. White W J, Sarraf K M, Schranz P.calcific deposition in the lateral collateral ligament of the knee.J Knee Surg. 2013 Dec;26 Suppl 1:S116-9. doi: 10.1055/s0032-1324815. Epub 2012 Sep 21.

8. Symptomatic calcification of the lateral collateral knee ligament.Hyoung Soo Kim, Jeong Hyun Yoo, Hwan Hee Cho, Sang Hyoung Soo Kim, Jeong Hyun Yoo, Hwan Hee Cho, Sang yeop Yi, Won Ha Bae, Yong Hoon Kim. Calcification of the lateral collateral ligament of the knee- A case report: Vol 21, No 4, Dec 2009.

9. Shenoy P M, Kim D H, Wang K H, Oh H K, Soo L C, Kim J H, Nha K W. Calcific tendinitis in popliteus tendon: arthroscopic excision and biopsy. Orthopedics, 2009 Feb; 32(2): 127.

10. B. Ozkurt, T. Sen, D. Cankaya, S. Kendir, K. Basarır, Y. Tabak. The medial and lateral epicondyle as a reliable landmark for intra-operative joint line determination in revision knee arthroplasty: Bone Joint Res 2016; 5: 280-286.

11. LaPrade R F, Ly $T$ V, Wentorf $F A$, et al. The posterolateral attachments of the knee: a quantitative and qualitative morphologic analysis of the fibular collateral ligament, popliteus tendon, popliteofibular ligament, and lateral gastrocnemius tendon. Am J Sports Med. 2003; 31: 854-860.

12. Evan W. James, B S, Christopher M. LaPrade, B A and Robert F. LaPrade, MD, Ph.D., Anatomy and Biomechanics of the Lateral Side of the Knee and Surgical Implications: Sports Med Arthrosc Rev. Volume 23, Number 1, March 2015. 